\title{
The Development of Home-School Partnership Courses: A Practice Based on Xingzhi Tao's Life Education Theory
}

\author{
Fengping Zhao, Chuanguo Wei \\ Shandong 271 Education Group, Shandong, China
}

\begin{abstract}
Home-school partnership plays a critical role in student growth and the home-school partnership courses provide important paths to achieving ideal results of the partnership. Under the guidance of the three principles of "life is education", "society is school" and "integrating teaching, learning and practice" in Xingzhi Tao's life education theory, Shandong 271 Education Group developed the parent school course and the family civilization course, which turn out to be a systematic support for the homeschool partnership program. This paper analyses the status quo of home-school cooperation in China and focuses elaborations on the components and practice of the two courses in Shandong 271 Education Group.
\end{abstract}

Science Insights Education Frontiers 2021; 10(2):1439-1449.

Doi: 10.15354/sief.21.or065

How to Cite: Zhao, F., \& Wei, C. (2021). The development of home-school partnership courses: A practice based on Xingzhi Tao's life education theory. Science Insights Education Frontiers, 10(1):1439-1449.

Keywords: Life Education, Xingzhi Tao, Home-School Partnership, Course, Goal, Path

About Authors: Chuanguo Wei, Shandong 271 Education Group, Shandong, China. E-mail: hzzxwcg@126.com

Correspondence to: Fengping Zhao, Shandong 271 Education Group, Shandong, China. E-mail:

zhaofengping5138@163.com

Conflict of Interests: None.

(C) 2021 Insights Publisher. All rights reserved.

Creative Commons NonCommercial CC BY-NC: This article is distributed under the terms of the Creative Commons Attribution-NonCommercial 4.0 License (http://www.creativecommons.org/licenses/by$\mathrm{nc} / 4.0 /$ ) which permits non-commercial use, reproduction and distribution of the work without further permission provided the original work is attributed by the Insights Publisher. 
$\mathrm{H}$

OME-SCHOOL partnership in this paper refers to the cooperation between families and schools in student education with the goal of promoting student healthy and comprehensive development. This concept originated in the USA, also expressed as "parental involvement" and "school, family, and community partnerships." There has been a consensus among scholars that families and schools should give full play to their respective advantages and make joint efforts in children's development through effective programs (Epstein, 2001). Since 1950s, home-school partnership has been drawing increasing attention from researchers, and gradually become an important trend in global educational development. Home-school educational cooperation in China was brought back to the right track in the 1980s and has been attached importance ever since. The life education theory of Xingzhi Tao (one of the most influential educators in the 20th century in China) provides an important theoretical support for current practice of home-school partnership in China. In particular, the three principles of "life is education", "society is school" and "integrating teaching, learning and practice" from Tao's theory are of great significance in guiding home-school partnership.

Currently, problems exist in home-school educational partnership, including disagreement over educational goals, lack of diverse partnering vehicles and ambiguity of family-school responsibility division, which might compromise the effectiveness of partnership or even lead to conflicts between parents and schools. Schools, as the dominant factor in home-school partnership, should take on the responsibility to explore new paths of home-school cooperation and build appropriate patterns for the partnership. Shandong 271 Education Group, a private 12-year boarding school conglomerate with more than 80000 students, has conducted fruitful exploration in creating home-school partnership program. This paper tries to discuss how to apply Xingzhi Tao's life education theory to the design of home-school partnership courses and explain the effectiveness of the courses in in-depth cooperation between families and schools.

\section{The Evolution of Study on Home-School Partnership and its Status Quo in China}

\section{The Evolution of Research on Home-School Partner- ship}

Home-school partnership originated among the 18th century immigrants in the United States. In the 1950s and 1960s, the issue of home school cooperation attracted considerable attention in countries with highly developed education such as European counties, the United States, South Korea, and Japan, where parents' right to participate in school education is guaranteed through legislation. With deepened research, scholars found that apart from schools, families and communities had impacts on adolescents' study as well (Hobbs, 1978). Bronfenbrenner (1994) further divided the external environment 
affecting teenagers' development into four systems: micro, medium, foreign, and macro. Coleman (1997) introduced the social capital theory into education. He summarized parental attention to children, family educational investment, parental educational expectation, parent-child interaction, and parents' social network as family social capital. Through a survey, he found that students from families with relatively more social capital had lower dropout rate and better academic performance. This conclusion was supported by the Coleman Study (Coleman, 1966), which indicated that family variables explained about half to two-thirds of the differences in students' academic performance. Epstein (2001) consolidated families, schools, and other social institutions in examining their roles in educational partnership and believed that the influence of school, family and community on children's education was not generated separately, but rather simultaneously and continuously. Given the above studies, a relatively complete theoretical foundation has been established for the research of home-school partnership.

\section{The Status Quo of Home-School Partnership in China}

The first study on home-school partnership in China was published in the column of "family and school child education" in People's Education in 1950. For more than 70 years since then, the issue of home school partnership has been studied by scholars from different fields to promote family and school cooperation in education. The Ninth Five Year Plan for Family Education jointly promulgated by All-China Women's Federation and the State Education Commission in 1996 represented China's first attempt in legislating family education. By the time of publication of the Family Education Promotion Law of the People's Republic of China on October 23, 2021, the contents and methods of family education had been continuously enriched and improved.

However, home-school partnership in China still face difficulties, mainly reflected in the incongruent home-school education goals, limited partnering vehicles and ambiguous division of family-school responsibility.

\section{Lack of Identity in Student Education Goals}

Due to insufficient exchange between parents and schools, the consensus on child education goals has not been reached. Understandings of the essence of education differ among families and schools. Particularly, traditional authoritative family education ideas still prevail, in which students can merely act as passive recipients of knowledge; Excessive emphasis on test scores is accepted consciously or unconsciously. In our current educational culture, neither is students" identity as "pro-active learners" and "selfeducators" well recognized, nor is students" spiritual growth fully respected (Gao, 2019).

\section{Limited Partnering Avenues}

Home-school partnership consists of interactive activities, which require mutual understanding and coordination between families and schools. Nevertheless, in current homeschool interactions, teachers typically have difficulty in obtaining parents' support due 
to limited opportunities of communication with parents. Parent meetings and home visits are almost the only avenues for home-school interactions.

\section{Ambiguous Home-School Responsibility Division}

From the perspective of social interdependence theory, some scholars define homeschool partnership as a process in which families and schools gradually form a positive interdependent mechanism through continuous interactions and discussions, and propose three cooperation patterns, namely "home-based cooperation", "school-based cooperation" and "home-school mutual assistance" (Li \& Yue, 2018). However, in practice, it is difficult to determine the respective responsibilities of parents and schools. At one extreme, in present school-dominated partnership, schools tend to take on all the educational responsibilities while parents seldom participate in school activities. At the other extreme, some teachers might transfer part of their professional obligations to families, requiring parents to tutor children in schoolwork. In addition, some parents are reckless enough to try to interfere in school operation, causing trouble to normal teaching order. Thereby, the obscured responsibility division and the sequential conflicts become predicaments in home-school partnership in China.

\section{Home-School Partnership Components in Xingzhi Tao's Educational Theories}

Xingzhi Tao was a great educator in China, devoting all his life to the cause of education and making pioneering contributions to the modernization of Chinese education. He not only established his own educational thought, but also conducted much educational practice. The life education theory is the cornerstone of Tao's educational thought, emphasizing education for life, education with life, and education for progressive needs in life. It is a multi-level, continuously developing and systematic educational theory (Zhang, 2017).

The three well-known principles of the life education theory are "life is education", "society is school" and "integrating teaching, learning and practice." Among them, "life is education" is the soul of the theory, meaning education is a lifelong coexistence with human life. "Society is school" emphasizes the need to establish an ideal learning-oriented society and to turn the whole society into a big school. "Integrating teaching, learning, and practice" is put forward as a methodology of the theory, highlighting the leading role of practice in the three principles and the necessity of acquiring knowledge from practice $(\mathrm{Hu}, 2007)$.

Tao's life education theory is about education on life and more importantly, about education of outlook on life. Education is not only derived from and for life, but also has the great mission of transforming the world. Tao proposed that life education should cultivate living capability and creativity and foster the consciousness of making a difference to the society. For students, participation in social life is mainly realized 
through school life and family life. Therefore, home-school partnership is a powerful means to achieve the goal of life education.

Based on the life education theory, 271 Education Group succeeds in developing the parent school course and the family civilization course after 13 years of exploration. "Life is education" ascertains the value of the two courses, "society is school" determines the components of the courses, and "integrating teaching, learning and practice" provides measures of implementation. The two home-school partnership courses provide paths to the success of students' life education.

\section{The Design of Home-School Partnership Courses Based on Tao's Life Education Theory}

\section{The Value and Goal of Home-School Partnership Courses Oriented by the Principle of "Life is Education"}

According to the principle of "life is education", the relationship between life and education is that life determines education and education in turn transforms life. The homeschool partnership program centers itself on life, including students' school life and family life, to trigger parents' interest of participation. Students perceive life, wisdom, and truth in their growth first through their physical senses. Practical activities in life are the most important means for students to perceive the world and realize healthy growth. We set student lifelong development as the goal of our program to guide parents, teachers, and students to give up utilitarian and biased educational ideas.

From the perspective of student development, we pursue student physical wellbeing, academic success, passion for life, strong thinking and learning ability, good self-management skills and leadership ability. In addition, in life education, students learn to take responsibility, responsibility for life, for family, and for society. Only by experiencing responsibility assumption can students acquire the ability to take responsibility.

Moreover, home-school partnership program is also aimed at promoting parent and school development. Teachers learn about students' study and life at home through home-school interactions, which help design personalized teaching to individual needs; Schools can take constructive suggestions from parents to improve educational quality. When it comes to parents, the program guides them to reflect on what "true education" is and warns them of the prevalent utilitarian pursuit in education; It reminds parents to make the best of family education and housework to cultivate children's practical skills; It advises parents on how to build a democratic family relationship with mutual respect and support; It encourages parents to learn, to read, and to think so that they can be role models and lifelong mentors for their children. 


\section{Components of Home-School Partnership Courses Based on the Principle of "Society is School"}

"Society is school" advocates connection between society and education, and utilization of all social components as educational resources. In the process of student growth, parents are the best educational resources, families are the best learning locations, and home-school partnership is the best social resources. Based on the needs of life and the goal of students' life education, 271 Education Group designed the contents of homeschool partnership courses.

\section{The Parent School Course}

As social beings, students are directly affected by parents' values, ways of thinking, behavior patterns and lifestyle. Therefore, the core objective of the parent school course is to educate parents to understand the value and significance of education, and to give up irrational pursuit of test scores. After a series of training and participation, parents can accept correct educational ideas, and a bridge will be built between school and family education. The parent school course consists of four modules, namely educational value module, positive acceptance module, teaching management experience module and parent-child mutual appreciation module.

\section{Educational Value Module}

Educational value module is composed of topic-based lectures and training with focus on educational basics, child overall growth, parent-child communication. Experts and headmasters are invited to give lectures to parents of all students in the school and training is provided by each grade on topics such as how to face angry children, what else to be done in family education, to be smart parents, love education, how to be good listeners, appreciation education. Training on different topics is provided to divided groups of parents, during which professional family education tutors and teachers will guide parents on how to deal with parent-child relations. Therefore, this module helps parents and teachers reach agreement in their understanding of educational value and goals. The results of the parent school course are assessed each semester at grade level to incorporate parental education into the class and grade teaching management systems.

\section{Positive Acceptance Module}

This module is intended to increase parents' awareness that all children have their own characteristics and that they should be accepted as unique individuals. The module includes two parts: i) special training on how to accept children positively, in the form of weekly lecture (online or offline) named Parent Lecture Room. It mainly dwells on two topics: "Every child has unique talent" and "every child is different;" ii) parent club activities, through which parents exchange ideas and skills in interaction with children. 


\section{Teaching Management Experience Module}

Parents are invited regularly to participate in classroom activities. It provides parents the opportunity to witness the school teaching models, observe children's performance in class and evaluate teachers' classroom practice; Meantime, parents have the chance to recall their role as students by experiencing classroom learning and classroom atmosphere. Moreover, parents with professional expertise are invited to give lectures to children to experience the role of teacher. Through this module, parents become better learners and educators, and can create a better environment for their children's growth at home.

In addition, parents are also invited to participate in students' extracurricular activities, such as watermelon grafting, Mount Tai root tracing tour in Qufu, Yangjiabu wood engraving picture appreciation tour, 65-kilometer hiking, as well as community service and voluntary activities in winter and summer vacations. Schools organize various festivals regularly including food festival, science and technology festival, reading festival, art festival and New Year party. Parents are involved in the organization of these events in different ways; Some even contribute their social resources to the festivals. Participation in extracurricular activities enables parents a comprehensive knowledge of children's study and life in school and helps build a close and harmonious parent-child relationship.

\section{Parent-Child Mutual Appreciation Module}

The school regularly organizes activities like Appreciation Week to make students aware of parents' love for them and their commitment to family and work, to stimulate children's gratitude for parents' devotion. In the school where all kinds of children live and study together, parents witness the differences among children and find their own children's unique personalities and strengths. They will realize that education progress slowly, and it demands patience to wait for children's talent to be released. A holiday activity called Family Appreciation Week is designed for children and parents to spot each other's strengths, to appreciate each other, and to enhance children's selfconfidence and harmonious parent-child relationship.

\section{Family Civilization Course}

Life education at home in terms of family virtues, wisdom enlightenment, healthy lifestyle, art and aesthetics, housework training, interpersonal relationship and responsibility assumption is imposed on children by parents in spontaneous or conscious ways. It is greatly influenced by social customs and family cultural traditions and typically exhibited in the forms of family rules and styles. Given this, the Group designed the family civilization course with four modules covering reading, home democracy, housework, and social life.

Reading Module 
The reading module is targeted at creating an educationally oriented family atmosphere. According to the book list recommended by the school, parents and children make respective reading plans with detailed requirements such as reading list and reading time. Parents are asked to spend no less than two hours a week in reading and sharing their reading insights with their children; They are also asked to upload reading-related photos and insights onto online reading group to be assessed if they have reached the parent-child reading standards. This reading plan triggers parents' and children's strong interest in reading, which certainly helps improve their competence.

\section{Home Democracy Module}

Family civilization is a matter not only for parents, but also for children. Only when parents and children interact effectively can family civilization progress become possible. Home democracy module advocates that all family members have an equal right to be involved in running the family. Parents and children take turns to act as family CEO so that children can participate equally in the decision-making of all family affairs, ranging from family financial plan and family tour plan to daily three meals. Such practice helps develop children's awareness of democracy and decision-making ability and build a harmonious family relationship of equality and mutual assistance among family members.

\section{Housework Treatment Module}

This module covers mainly housework such as washing dishes, mopping the floor and personal sanitation tasks as well as food preparation. In doing housekeeping, children not only learn housework skills and enjoy work results, but also experience the heavy loads and triviality of housework, which can educate them to develop good habits. In turn, children's behavior can drive parents to do better in sanitary maintenance, sundries storage and even public welfare behavior such as garbage sorting and old clothes donation.

In food preparation, by purchasing ingredients, cooking delicious food together with parents and cleaning up after dinner, children learn essential life skills and develop structured thinking ability. Cooking itself is a good way to make children deft, to develop intelligence and grow wisdom. Moreover, through meal preparation, children can fully perceive the life burden of their parents and the tacit understanding between parents and children is enhanced.

Life education is a generative process. With the experiential learning in doing housework, students not only acquire life skills, but also build up faith and courage to create the future.

\section{Social life Module}

This module includes three parts, that is, social life etiquette, social life experience and social life summary. First, parents are required to impart social life etiquette to their children, and children can also collect and learn the rules through the Internet. Then 
parents take children to experience social life to further internalize the previously informed rules and manners. Finally, the process of social life is reviewed, and the lessons summarized. Through social life, parents can guide children to integrate themselves into society and children can perceive what is meant by the idea "society is school, society is life, and life is education."

\section{Practical Application of the Home-School Partnership Courses Based on the Principle of "Integrating Teaching, Learning and Practice"}

\section{Guiding Roles of Home-School Partnership Courses in Student, Teacher, and Parent Development.}

The home-school partnership program has a significant positive effect on student comprehensive development. Through special training, children understand the objectives, contents, implementation measures and assessment methods of the family civilization course. In activities designed for the courses, children and parents make decisions on family affairs, read, exercise, and do housework together.

Furthermore, the program has become a powerful motivator in teachers' professional development. To communicate effectively with parents, teachers must improve their academic competence. Teachers with 271 education group are conscientiously studying the history of their respective disciplines and devoting their time and energy to the study on twelve-year curriculum integration; Their teaching level is continuously improved by the selection of excellent teaching models and a wide range of exchanges with other academic institutions; Through special training centered on family education, teachers are better informed of family education skills and create smooth home-school communication channels; Finally, training in curriculum integration, classroom teaching and family education enhances teachers' overall educational competence and can generate more productive home-school cooperation.

The parent school course effectively promotes parental involvement in child education. Parents obtain full understanding of school curriculum and management in an all-round way by supervising curriculum implementation, participating in classroom activities, and taking part in various extra curriculum activities; Parental study group, writing group and reading club are set up to integrate parents into the school-family community. In the process of participation, parents deepen their understanding of the value of education and acquire the opportunity to know their children better. In addition, the program also helps parents form habits of reading, writing and reflection, and become real learners, researchers, and educators.

\section{Operating Mechanisms for Home-School Partnership Program}

The operating mechanism of family committee ensures the successful implementation of home-school partnership program. The three-level parent committee (school, grade, 
and class) with a separate office on the campus have established rules and regulations for parental participation in child education. The parent committee take part in formulating schoolwork plan at the beginning of the semester and summary report at the end of the semester and participates in major school events. Other parents (three to five persons per day from each class) take turns to be present on campus to watch the classroom activities, participate in school research and interview teachers and students so that they can be involved in various school affairs in an organized and regular manner. Meantime, they can experience children's daily study and life including three meals and sleep; The time they spend with teachers and children on campus make their relationships closer.

The parent school course and the family civilization course are routinized and institutionalized. They are organized with implementation plans, timetabled sessions, and feasible approaches. The courses are welcomed by students and well recognized by parents due to the clear objectives, concrete contents, and ever improving assessment methods.

To give full play to the role of model parents, the school empowers the family committee to select excellent parents and commend them regularly so that their practice and experience can be shared with other parents. In mid-term and terminal assessments, the school selects the excellent individuals and teams in the implementation of the two courses and use models' stories to motivate all parents to be fully involved in the homeschool partnership program.

\section{Conclusion}

Homes and schools are the most important factors influencing students' life and growth. Based on the three principles of "life is education", "society is school" and "integrating teaching, learning and practice" in Tao's life education theory, the parent school course and the family civilization course developed by Shandong 271 Education Group have been playing significant roles in home-school partnership. Both parents and schools have made the best of their respective advantages to complement each other in child education. In the 13-year practice, the objectives, contents, implementation measures of the courses have gradually improved. They become effective platforms for in-depth cooperation between families and schools, through which the efforts of students, parents and teachers are integrated to promote students' comprehensive growth.

\section{References}

Bronfenbrenner, U. (1994). Ecological models of human development. In International En- cyclopedia of Education, Vol. 3, 2nd. Ed.:

1643-1647. Oxford: Elsevier. 
Coleman, J.S. (1966). Equality of Educational Opportunity. National Center for Educational Statistics (DHEW/OE), Washington, DC.

Coleman, J.S. (1997). Family, school, and social capital. In L. J. Sara (Ed.), International Encyclopedia of the Sociology of education (pp. 623-625). Oxford: Pergaman Press.

Epstein, J.L. (2001). Building bridges of home, school, and community: The importance of design. Journal of Education for Students Placed at Risk, 6(1-2):161-168. https://doi.org/10.1207/S15327671ESPR060 $1-2 \quad 10$

Gao, X.N. (2019). Home-school partnership: Standard, dilemma, and breakthrough paths. Elementary Education Studies, 2019(12):8687.

Hobbs, N. (1978). Families, Schools, and Communities: An Ecosystem for Children. Teachers College Record, 79(4):756-766.
Hu, X.F. (2007). Tao Xingzhi's Educational Works. Chengdu: Sichuan Education Press.

Jeynes, W.H. (2007). The relationship between parental involvement and urban secondary school student academic achievement: A meta-analysis. Urban Education, 42(1):82110. DOI:

https://doi.org/10.1177/0042085906293818

Li, Q.C., \& Yue, D.Q. (2018). The construction and application of the basic structure of home school cooperation. Journal of the Chinese Society of Education, 2018(12):3842.

Xia, Q. (2019). Home school partnership: From "separate education" to "cooperative education.” Jiangsu Education, 2019(47):66-69.

Zhang, H. (2017). Tao Xingzhi's outlook on life education: Connotations, values, and ideals. Forum on Chinese Culture, 2017(2):54-60.

Received: 26 October 2021

Revised: 05 November 2021

Accepted: 03 December 2021 